\title{
Impact of selected solvent systems on the pore and solid structure of cellulose aerogels
}

\author{
Nicole Pircher • Leticia Carbajal • Christian Schimper • Markus Bacher • \\ Harald Rennhofer · Jean-Marie Nedelec $\cdot$ Helga C. Lichtenegger • \\ Thomas Rosenau $\cdot$ Falk Liebner
}

Received: 20 August 2015/Accepted: 28 February 2016/Published online: 7 March 2016

(C) The Author(s) 2016. This article is published with open access at Springerlink.com

\begin{abstract}
The impact of selected cellulose solvent systems based on the principal constituents tetrabutylammonium fluoride (TBAF), 1-ethyl-3-methyl-1 $\mathrm{H}$ imidazolium-acetate, $N$-methylmorpholine- $N$-oxide, or calcium thiocyanate octahydrate (CTO) on the properties of cellulose II aerogels prepared from these solvent systems has been investigated as a means towards tailoring cellulose aerogel properties with respect to specific applications. Cotton linters were used as representative plant cellulose. Cellulose was coagulated from solutions with comparable cellulose content, and dried with supercritical carbon dioxide after solvent exchange. The resulting bulk aerogels were comprehensively morphologically and mechanically tested to relate structure and mechanical properties. Different solvent systems caused considerable
\end{abstract}

Electronic supplementary material The online version of this article (doi:10.1007/s10570-016-0896-z) contains supplementary material, which is available to authorized users.

N. Pircher - C. Schimper · M. Bacher .

T. Rosenau $\cdot$ F. Liebner $(\bowtie)$

Division of Chemistry of Renewable Resources,

University of Natural Resources and Life Sciences

Vienna, Konrad-Lorenz-Straße 24, 3430 Tulln, Austria

e-mail: falk.liebner@boku.ac.at

L. Carbajal · J.-M. Nedelec

Institute of Chemistry of Clermont-Ferrand, Clermont

Université, Ecole Nationale Supérieure de Chimie de

Clermont-Ferrand, BP 10448, 63000 Clermont-Ferrand,

France differences in the properties of the bulk samples, such as internal surface area (nitrogen sorption), morphology, porosity (He pycnometry, thermoporosimetry), and mechanical stability (compression testing). The results of SAXS, WAXS, and solid-state ${ }^{13} \mathrm{C}$ NMR spectroscopy suggest that this is due to different mechanisms of cellulose self-assembling on the supramolecular and nanostructural level, respectively, as reflected by the broad ranges of cellulose crystallinity, fibril diameter, fractal dimension and skeletal density. Both solid state NMR and WAXS experiments confirmed the sole existence of the cellulose II allomorph for all aerogels, with crystallinity reaching a maximum of 46-50\% for CTO-derived aerogels. Generally, higher fibril diameter, degree of crystallinity, hence increased skeletal density were associated with good preservation of shape and dimension throughout conversion of lyogels to aerogels, and enhanced mechanical stability, but somewhat reduced specific surface area. Amorphous, yet highly rigid

\section{Carbajal · J.-M. Nedelec \\ UMR 6296, Institute of Chemistry of Clermont-Ferrand, Centre National de la Recherche Scientifique, 24 Avenue des Landais, 63171 Aubière, France}

H. Rennhofer · H. C. Lichtenegger Institute of Physics and Material Sciences, University of Natural Resources and Life Sciences Vienna, Peter Jordan Straße 82, 1190 Vienna, Austria 
aerogels derived from TBAF/DMSO mixtures deviated from this trend, most likely due to their particular homogeneous and nanostructured morphology.

Keywords Cellulose aerogels - Cellulose solvents · Porous solids - Thermoporosimetry

\section{Introduction}

Aerogels are solids consisting of a coherent openporous network of loosely packed, bonded cellulose particles or nanofibrils whose voids are filled with gases, such as air, and feature very low density and high specific surface area (Liebner et al. 2012a). Depending on the source material and preparation method, their solid structure can consist of the cellulose polymorphs I (I $\alpha$ : dominating in bacterial cellulose; I $\beta$ : principal crystal phase of native plant cellulose) or II, the sole allomorph of cellulose coagulated from solution state. In any case, intrinsic characteristics of the cellulosic source material, such as molecular weight average and distribution or purity-for example in terms of residual lignin content in wood pulp or content of carboxyl- and carbonyl groups-substantially govern the material properties of the derived aerogels. For cellulose II aerogels-the target material of this study-morphology and mechanical properties can be furthermore controlled by the type of solvent used to shape aerogels from solution state.

Cellulose solvents share the capability to disrupt and rearrange the complex intra- and inter-molecular hydrogen bond networks in the different cellulose allomorphs, thereby achieving cellulose solubility. Several solvents have previously been used for the preparation of cellulosic aerogels, including molten $\mathrm{Ca}(\mathrm{SCN})_{2} \cdot \mathrm{nH}_{2} \mathrm{O}$, an inorganic salt hydrate (Hoepfner et al. 2008; Jin et al. 2004), aqueous alkali hydroxides, such as aq. $\mathrm{NaOH}$ (Cai et al. 2008; Gavillon and Budtova 2008) or aq. LiOH (Cai et al. 2008) [often under addition of solubilizing additives such as urea (Cai et al. 2008) or thiourea (Zhang et al. 2012)], a range of low-melting organic salts (ionic liquids) (Aaltonen and Jauhiainen 2009; Sescousse et al. 2011), and the tertiary amine oxide $N$-methylmorpholine- $N$-oxide monohydrate $\left(\mathrm{NMMO} \cdot \mathrm{H}_{2} \mathrm{O}\right)$, which is used in the large-scale production of Lyocell fibers
(Innerlohinger et al. 2006; Liebner et al. 2009). A comprehensive summary of cellulose solvents with focus on manufacture of cellulosic aerogels, including particularities regarding their cellulose dissolving performance, handling throughout the processing chain and state of knowledge regarding their impact on the morphology of the aerogels cellulose aggregate structure, can be found in the encyclopedia chapter Cellulose-based aerogels (Liebner et al. 2015).

While efforts regarding the characterization of cellulosic aerogels are commonly focusing on bulk density, pore volume, pore size distribution, response towards compressive stress, and putative internal surface morphology, as studied by ESEM or SEM on fragments taken from the interior of the aerogel by gentle plucking, there is no comprehensive study on the effect of different solutions on the solid structure, such as crystallinity, nanostructure etc.

In this work, the impact of different cellulose solvents on the properties of lightweight cellulose II aerogels $\left(\rho<70 \mathrm{mg} \mathrm{cm}^{-3}\right)$ obtained from cotton linters as a representative source of plant cellulose, has been investigated with regard to bulk properties, pore features and cellulose aggregate structure. To this end, four cellulose solvent systems, namely mixtures of (1) tetrabutylammonium fluoride and DMSO (TBAF/DMSO), (2) 1-ethyl-3-methyl-1 $H$-imidazolium acetate and DMSO ([EMIm][OAc]/DMSO), (3) calcium thiocyanate octahydrate and lithium chloride (CTO/LiCl), and (4) molten $N$-methylmorpholine- $N$-oxide monohydrate $\left(\mathrm{NMMO} \cdot \mathrm{H}_{2} \mathrm{O}\right)$, have been studied. While each of these cellulose solvents has certain pros and cons with regard to cellulose dissolution, coagulation and conversion of cellulosic lyogels to aerogels, calcium thiocyanate octahydrate (CTO) is considered the most promising solvent due to its low costs and environmental impact.

The morphology of the obtained fragile open porous ductile materials was studied by scanning electron microscopy (SEM). Small angle X-ray scattering (SAXS) was used to determine fractal dimension and average size of the cellulose fibrils forming the respective scaffolds. Cellulose crystallinity was determined by both wide-angle X-ray scattering (WAXS) and solid-state ${ }^{13} \mathrm{C}$ NMR spectroscopy. Possible thermal and chemical degradation of cellulose induced by the different dissolution approaches was evaluated by size exclusion chromatography. Skeletal density of the cellulose nanofibrils was 
measured by helium pycnometry allowing for calculation of sample porosity. Thermoporosimetry analysis was used to obtain pore size distributions comprising the full nanometer and low micrometer range. Internal surface areas were calculated from nitrogen adsorption/desorption experiments at $77 \mathrm{~K}$ and SAXS studies.

The comprehensive study of the nanostructure and material properties of the cellulose II aerogels was carried out to evaluate the influence of the respective cellulose solvent system with the aim of tailoring aerogel properties for a wide range of promising applications.

\section{Materials}

Calcium thiocyanate hydrate $\left[\mathrm{Ca}(\mathrm{SCN})_{2} \cdot n \mathrm{H}_{2} \mathrm{O}\right]$ was synthesized from calcium hydroxide and ammonium thiocyanate (Pircher et al. 2015). $N$-benzylmorpholine- $N$-oxide (NBnMO), added as sacrificial scavenger of carbenium iminium ions, which autocatalytically decompose NMMO$\cdot \mathrm{H}_{2} \mathrm{O}$ under cellulose dissolving conditions, was prepared according to a method described in an earlier work (Liebner et al. 2012b). Lithium chloride ( $\mathrm{LiCl}$ ), propyl gallate $(\mathrm{PG})$ and tetrabutylammonium fluoride trihydrate $\left(\mathrm{TBAF} \cdot 3 \mathrm{H}_{2} \mathrm{O}\right)$ were purchased from Sigma-Aldrich (Vienna, Austria). Dimethyl sulfoxide (DMSO) was a product of Merck (Vienna, Austria). 1-Ethyl-3-methyl-1Himidazolium acetate ([EMIm][OAc]) was a donation of BASF (Ludwigshafen, Germany). Absolute ethanol was purchased from Fisher Scientific (Vienna, Austria). $N$-methylmorpholine- $N$-oxide monohydrate (NMMO $\cdot \mathrm{H}_{2} \mathrm{O}$ ) was of technical grade. Cotton linters (CL, $\mathrm{M}_{\mathrm{w}} 133.5 \mathrm{~kg} \mathrm{~mol}^{-1}, \mathrm{CCOA} 4.2 \mu \mathrm{mol} \mathrm{g}^{-1} \mathrm{C}=\mathrm{O}$, FDAM $8.8 \mu \mathrm{mol} \mathrm{g}^{-1} \mathrm{COOH}$ ) were used as a cellulose source.

Preparation of cellulose II lyogels using different cellulose solvent/anti-solvent systems

Prior to dissolution, cotton linters were activated by disintegration in deionized water using a kitchen blender for about $30 \mathrm{~s}$ and subsequent swelling in deionized water. For all solvent exchange steps sample-to-liquid volume ratios of 1:10 were maintained.
$\mathrm{NMMO} \cdot \mathrm{H}_{2} \mathrm{O}$

Cellulose aerogels according to the Lyocell route were prepared by dissolving $3 \mathrm{w} \% \mathrm{CL}$ in NMMO $\cdot \mathrm{H}_{2} \mathrm{O}$. $1 \mathrm{w} \%$ PG and $1 \mathrm{w} \%$ NBnMO were added to suppress homogeneous and heterogeneous side reactions (Rosenau et al. 2002, 2005). A visually clear cellulose solution was obtained after 20 min of vigorous stirring at $110{ }^{\circ} \mathrm{C}$. The Lyocell dope was cast into cylindrical molds ( $\varnothing 10 \mathrm{~mm}, \mathrm{~h} 10$ or $20 \mathrm{~mm}$ ) and solidified upon cooling to room temperature. Cellulose coagulation was achieved by immersion of the samples in $96 \%$ ethanol. Subsequently, leaching of the cellulose solvent including the stabilizers and simultaneous transfer to a solvent miscible with $\mathrm{scCO}_{2}$ was accomplished by immersion in absolute ethanol, which was replaced three times every $24 \mathrm{~h}$.

\section{$\mathrm{Ca}(\mathrm{SCN})_{2} \cdot 8 \mathrm{H}_{2} \mathrm{O} / \mathrm{LiCl}$}

1.5 or $2.0 \mathrm{w} \% \mathrm{CL}$ were dissolved in a melt consisting of $\mathrm{Ca}(\mathrm{SCN})_{2}$, deionized water and $2.5 \mathrm{w} \% \mathrm{LiCl}$. Prior to heating of the solvent system, the actual water content of $\mathrm{Ca}(\mathrm{SCN})_{2}$ was determined by Karl-Fischer titration and adjusted to a molar ratio of 8:1 $\left(\mathrm{H}_{2} \mathrm{O}: \mathrm{Ca}^{2+}\right)$ corresponding to the highest coordination number of calcium ions (Hoepfner et al. 2008). Full dissolution of cotton linters in freshly prepared $\mathrm{CTO} / \mathrm{LiCl}$ melt was achieved within 120 min of agitation at $140{ }^{\circ} \mathrm{C}$, as confirmed by light microscopy (NOVEX Holland, B-Series, 200× magnification). Subsequently, vacuum was applied to remove air bubbles from the viscous cellulose solution.

The hot cellulose solution was cast into the abovedescribed molds, cooled to room temperature and covered with an excess of $96 \mathrm{v} \%$ ethanol to coagulate the cellulose. The solidified bodies were subsequently transferred into aqueous $50 \mathrm{v} \%$ ethanol and then repeatedly immersed in deionized water until conductivity of the washing bath was below $1 \mu \mathrm{S}$. Prior to $\mathrm{scCO}_{2}$ drying, the samples were immersed in absolute ethanol, which was replaced two times every 6-12 h.

\section{TBAF/DMSO}

A stock solution was prepared by dissolving $315.12 \mathrm{~g}$ TBAF$\cdot 3 \mathrm{H}_{2} \mathrm{O}$ in $684.88 \mathrm{~g}$ anhydrous DMSO $\left(1 \mathrm{~mol} \mathrm{~kg}^{-1}\right)$. The solvent mixture, which had a water content of $5.4 \mathrm{w} \% \mathrm{H}_{2} \mathrm{O}$ (determined by Karl- 
Fischer titration), was dried by adding $650 \mathrm{~g}$ molecular sieve $4 \AA$ (Sigma-Aldrich), until the water content was about $1.5 \mathrm{w} \%$ (TBAF $0.79 \mathrm{H}_{2} \mathrm{O}$ ). Subsequently, the stock solution was diluted with anhydrous DMSO to obtain a TBAF content of $16.6 \mathrm{w} \%$ and a water content of $0.8 \mathrm{w} \%$, respectively. For the preparation of cellulose solutions, the solvent mixture was pre-heated to $60{ }^{\circ} \mathrm{C} .3 \mathrm{w} \% \mathrm{CL}$ were added in portions and dissolved under gentle stirring for $24 \mathrm{~h}$. Casting of the cellulose solution and coagulation of cellulose was accomplished in the same way as described for the $\mathrm{Ca}(\mathrm{SCN})_{2} \cdot 8 \mathrm{H}_{2} \mathrm{O} / \mathrm{LiCl}$ solvent system. However, washing with water was not required due to the good solubility of TBAF in ethanol. Instead, removal of the cellulose solvent and simultaneous transfer to a solvent miscible with $\mathrm{scCO}_{2}$ was accomplished by immersion of the samples in absolute ethanol, which was replaced three times every $24 \mathrm{~h}$.

\section{[EMIm][OAc]/DMSO}

1.5 or $3.0 \mathrm{w} \% \mathrm{CL}$ were dissolved in a mixture of the ionic liquid [EMIm][OAc] and DMSO $(3: 7, \mathrm{v} / \mathrm{v})$ at room temperature under agitation. After $2 \mathrm{~h}, \mathrm{CL}$ were completely dissolved as confirmed by light microscopy. After degassing and casting the solutions into respective molds, the respective cellulose was coagulated by addition of $96 \%$ ethanol ( $c f$. CTO/LiCl solvent system). The removal of the cellulose solvent was accomplished by immersion in the cellulose antisolvent (96\% ethanol), which was replaced four times every 6-12 h. Prior to $\mathrm{scCO}_{2}$ drying, the samples were immersed in absolute ethanol, which was replaced two times every 6-12 $\mathrm{h}$.

\section{Supercritical carbon dioxide drying}

Extraction of the cellulose anti-solvent ethanol and conversion of the lyogels to aerogels was accomplished by supercritical carbon dioxide $\left(\mathrm{scCO}_{2}\right)$ drying. The samples were placed into a $300 \mathrm{~mL}$ autoclave equipped with a separator for carbon dioxide recycling (Separex, France). Drying was performed under constant flow of $\mathrm{scCO}_{2}\left(40 \mathrm{~g} \mathrm{~min}^{-1}\right)$ at $10 \mathrm{MPa}$ and $40{ }^{\circ} \mathrm{C}$ for $2-3 \mathrm{~h}$. The system was then slowly and isothermally depressurized at a rate of $<0.1 \mathrm{MPa} \min ^{-1}$.
Characterization

\section{Bulk density and shrinkage}

Shrinkage of the shaped cellulose solutions and the resulting lyogels during the coagulation/solvent exchange and supercritical carbon dioxide drying steps was evaluated by following the respective volumetric changes of the specimen at the respective stages. To calculate bulk densities, the weight of the aerogels was determined gravimetrically.

\section{Scanning electron microscopy}

Scanning electron microscopy (SEM) of gold sputtered samples (Leica EM SCD005 sputter coater, layer thickness $6 \mathrm{~nm}$ ) was performed on a Tecnai Inspect S50 instrument under high vacuum using an acceleration voltage of $5.00 \mathrm{kV}$.

\section{Mechanical testing}

Mechanical response profiles towards compressive stress were recorded on a Zwick-Roell Materials Testing Machine Z020. The required strain to achieve a deformation speed of $2.4 \mathrm{~mm} \mathrm{~min}^{-1}$ was measured with a $500 \mathrm{~N}$ load cell. Yield strength $\left(\mathrm{R}_{\mathrm{P} 0.2}\right)$ was defined as the stress at $0.2 \%$ plastic deformation.

\section{Small and wide angle $X$-ray diffraction}

X-ray scattering was performed on a Rigaku S-Max 3000 with $\mathrm{MM002}+\mathrm{Cu}-\mathrm{K}_{\alpha}$ source (wavelength $\lambda=0.154 \mathrm{~nm}$ ). Scattering images were averaged over the azimuth to obtain information on the intensity $\mathrm{I}(\mathrm{q})$ depending on the reciprocal lattice vector $\mathrm{q}$ which is related to the scattering angle $(2 \Theta)$, and the wavelength of the $X$-ray radiation $(\lambda)$ (Eq. 1):

$\mathrm{q}=4 \pi \sin (\Theta) / \lambda$.

The signals showed isotropic structure, i.e. no preferred orientation was detected for all materials. With the aim to access scattering vectors in range of 0.06-7 $\mathrm{nm}^{-1}$ (Small Angle X-ray Scattering, SAXS) and $5-25 \mathrm{~nm}^{-1}$, i.e. $8^{\circ}-38^{\circ} 2 \Theta$ (Wide Angle X-ray Scattering, WAXS), respectively, all samples were measured in different distances to the detector.

SAXS data were background-corrected and analyzed for the radius of cellulose nanofibrils forming 
the aerogel network and the fractal dimension (FD) of the network. Furthermore, the specific inner surface was calculated from the Porod constant (P), proportional to the pore surface (S), and by taking the scattering invariant (Inv) (Eq. 2) into account, which is proportional to the pore volume $(\mathrm{V})$. The ratio $\mathrm{P} / \mathrm{Inv}$ corresponds to the surface area-to-volume ratio of the pores in the sample volume irradiated by the X-ray beam (Eq. 3).

$\operatorname{Inv}=\int_{0}^{\infty} \mathrm{q}^{2} \mathrm{I}(\mathrm{q}) \mathrm{dq}$

$\mathrm{P} / \mathrm{Inv}=1 /\left(\pi \cdot \phi_{1} \cdot \phi_{2}\right) \cdot \mathrm{S} / \mathrm{V}$

where $\phi_{1}$ and $\phi_{2}=1-\phi_{1}$ are the volume fractions of the pores and the cellulose material.

The results of WAXS were used to calculate cellulose crystallinity (Eq. 4) based on a comparison of the intensities of the main visible peak at about $20^{\circ}$ $\left(\mathrm{I}_{\text {cryst }}\right)$ and of a peak at a position, which is assumed to show scattering from amorphous phases only, such as that at $13.2 \mathrm{~nm}^{-1}$, i.e. $18^{\circ}\left(\mathrm{I}_{\mathrm{amorph}}\right)$ (Xu et al. 2013). Prior to integration all spectra were baselinecorrected.

Crystallinity $_{\text {WAXS }}=\frac{I_{\text {cryst }}-I_{\text {amorph }}}{I_{\text {cryst }}} \cdot 100 \%$

\section{Solid state nuclear magnetic resonance}

All solid state nuclear magnetic resonance (NMR) experiments were performed on a Bruker Avance III HD 400 spectrometer (resonance frequencies of ${ }^{1} \mathrm{H}$ of $400.13 \mathrm{MHz}$ and ${ }^{13} \mathrm{C}$ of $100.61 \mathrm{MHz}$, respectively), equipped with a $4 \mathrm{~mm}$ dual broadband CP-MAS probe. ${ }^{13} \mathrm{C}$ spectra were acquired using the TOSS (total sideband suppression) sequence, spinning rate $5 \mathrm{kHz}$, cross-polarization (CP) contact time $2 \mathrm{~ms}$, recycle delay $2 \mathrm{~s}$, SPINAL-64 ${ }^{1} \mathrm{H}$ decoupling and acquisition time $43 \mathrm{~ms} .2 \mathrm{k}$ data points were sampled to give a spectral width of $240 \mathrm{ppm}$. Chemical shifts were referenced externally against the carbonyl signal of glycine ( $\delta 176.03 \mathrm{ppm})$. The acquired FIDs were apodized with an exponential function $(\mathrm{lb}=11 \mathrm{~Hz})$ prior to Fourier transformation. Peak fitting was performed with the Dmfit program (Massiot et al. 2002).
Size exclusion chromatography

Size exclusion chromatography (SEC) on a system comprising four columns (PLgel MIXED-A LS, $20 \mu \mathrm{m}, 7.5 \times 300 \mathrm{~mm}$ ), multiple-angle laser light scattering (MALLS) and refractive index (RI) detection, was performed to determine the molecular weight distribution of cellulose prior to and after processing to aerogels. The respective samples were activated using the standard method involving successive immersion in $\mathrm{H}_{2} \mathrm{O}$, ethanol and DMAc and subsequently dissolved in $\mathrm{N}, \mathrm{N}$-dimethylacetamide (DMAc)/LiCl $(9 \% \mathrm{w} / \mathrm{v})$. A mixture of DMAc/LiCl $(0.9 \% \mathrm{w} / \mathrm{v})$ was used as SEC mobile phase (Röhrling et al. 2002). Calculations were performed using a $\mathrm{dn} / \mathrm{dc}$ value of $0.136 \mathrm{ml} \mathrm{g}^{-1}$ (Schelosky et al. 1999).

\section{Thermoporosimetry}

An important characteristic of cellulosic aerogels is their hierarchical pore structure which co-determines their fascinating properties. However, it is not easy to analyze the entire pore size distribution (PSD) with only a single technique. Commonly, the PSD of aerogels is studied using mercury intrusion and nitrogen sorption methods. $\mathrm{N}_{2}$ sorption however only covers pore sizes of up to about $170 \mathrm{~nm}$, which is insufficient for the broad PSDs inherent to most cellulose-based aerogels (single-digit nano- to low micrometer range). Mercury intrusion is not an appropriate technique to characterize the fragile, ultra-lightweight cellulose aerogels, as the nanofibrillary network of soft matter is inevitably destroyed by this method. Therefore, the PSD can only be calculated from the bulk volume reduction (sample compression) rather than from intrusion of mercury into the pore system, which in fact does not occur (nonintrusive mercury porosimetry). After applying a certain mercury pressure, the PSD below the largest pore size affected by the densification can be characterized by nitrogen sorption experiments (Pirard et al. 2003; Rudaz et al. 2014).

Thermoporosimetry (TPM), a method relying on the Gibbs-Thomson equation (Eq. 5), has been proposed as an alternative technique to characterize the structure of porous aerogels (Gibbs 1928; Thomson 1872). The Gibbs-Thomson equation quantifies the 
experimental shift of the melting point of an interstitial liquid caused by its confinement in small pores and can be written as:

$\Delta \mathrm{T}=\mathrm{T}_{\mathrm{P}}-\mathrm{T}_{0}=\frac{2 \sigma_{\mathrm{SL}} \cos \theta \mathrm{T}_{0}}{\Delta \mathrm{H}_{\mathrm{m}} \rho_{\mathrm{s}} \mathrm{R}_{\mathrm{p}}} \sim \frac{\mathrm{k}}{\mathrm{R}_{\mathrm{p}}}$

where $T_{P}$ is the melting temperature of a liquid confined in a pore of radius $R_{p}, T_{0}$ is the normal melting temperature of the liquid, $\sigma_{\mathrm{SL}}$ is the surface energy of the solid/liquid interface, $\theta$ is the contact angle, $\Delta \mathrm{H}_{\mathrm{m}}$ is the melting enthalpy and $\rho_{\mathrm{S}}$ is the density of the solid.

According to this equation, the shift of the transition temperature of a confined liquid $\Delta \mathrm{T}$ is inversely proportional to the radius of the pore in which it is confined. It is, however, well known that not the entire solvent takes part in the transition and a significant part remains adsorbed onto the surface of the pore. The state of this adsorbed layer has been discussed extensively for the case of water. Consequently, the radius in the Gibbs-Thomson equation should be written as $R=R_{p}-t$ where $t$ is the thickness of the adsorbed layer leading to a reformulation of Eq. (5) as Eq. (6):

$\mathrm{R}_{\mathrm{P}}=\frac{\mathrm{k}}{\Delta \mathrm{T}}+\mathrm{t}$

In principle, it is then possible to determine the pore size of a given material by measuring $\Delta \mathrm{T}$. Kuhn et al. (1955) proposed to use differential scanning calorimetry to measure $\Delta \mathrm{T}$ and invented the so-called "thermoporometry" technique (or "thermoporosimetry" as will be used in the following). This technique has been further described by Fagerlund (1973) and popularized and developed by Brun et al. (1977). Knowledge of $\mathrm{k}$ and $t$ in Eq. (6) is mandatory, but once determined, the curve obtained from TPM can be transformed into the PSD. In this sense, TPM is a secondary method since it requires preliminary determination of the evolution of $\Delta T$ as a function of $R_{p}$ for a given solvent.

Based on previous studies investigating the applicability of $o$-xylene as a TPM solvent to determine the pore size distribution of silica aerogels (Dessources et al. 2012), the following equation was derived:

$\mathrm{R}_{\mathrm{P}}=\mathrm{t} \exp \left(\frac{-1}{\mathrm{c} \Delta \mathrm{T}}\right)$ where $\mathrm{t}=1.4919 \mathrm{~nm}$ is the thickness of the layer of the solvent remaining adsorbed onto the surface of the pores and $\mathrm{c}=0.03706{ }^{\circ} \mathrm{C}^{-1}$.

This mathematical model avoids simplification of the hypothesis and has proven to be the most suitable for this solvent in particular for the high value of $R_{p}$ inherent to cellulosic aerogels $(\leq 10 \mu \mathrm{m})$ (Billamboz et al. 2005).

Variation of solvent crystallization enthalpy as a function of temperature has to be taken into account for a correct calculation of PSD (Brun et al. 1977). Knowing the porous volume of the reference silica gels, this can be accomplished by considering the amount of $o$-xylene undergoing phase transition. The following dependence was found (Eq. 8):

$\mathrm{W}_{\mathrm{a}}=\mathrm{W}_{0} \exp \left(\frac{\Delta \mathrm{T}}{\mathrm{f}}\right)$

where $\mathrm{W}_{\mathrm{o}}=97.7 \mathrm{~J} \mathrm{~cm}^{-3}$ is the energy of crystallization of the bulk solvent and $\mathrm{f}=57.9^{\circ} \mathrm{C}$.

Considering Eqs. (7) and (8) derived for mesoporous systems, PSDs can be determined according to Eq. (9):

$\frac{\mathrm{dV}_{\mathrm{P}}}{\mathrm{dR}_{\mathrm{P}}}=\frac{\mathrm{Y}(\mathrm{T}) \Delta \mathrm{T}^{2} \mathrm{c}}{\mathrm{W}_{\mathrm{a}} \mathrm{R}_{\mathrm{P}}}$

where $\mathrm{Y}(\mathrm{T})$ is the heat flow of the sample given by the ordinate of the DSC thermogram.

In course of this work thermoporosimetry analysis was performed using a Mettler-Toledo DSC 823e differential scanning calorimeter (DSC) equipped with a liquid nitrogen module to extent the scanning range to $-150-600{ }^{\circ} \mathrm{C}$. Data processing was accomplished with the STARe software package. The DSC instrument was calibrated for both, temperature and enthalpy using open-porous metallic standards (In, $\mathrm{Pb}, \mathrm{Zn})$.

About $1-5 \mathrm{mg}$ of the respective aerogel was weighed into a $160 \mu$ l aluminum DSC pan and soaked with $o$-xylene in slight excess to ensure both quantitative filling of the aerogels voids and presence of some free solvent to allow the measurement of its crystallization upon cooling. Crystallization curves were used instead of melting curves, but reversibility of the transitions was confirmed by cycling the system. All measurements were carried out in ambient atmosphere and included the following steps: 
- Cooling from $25{ }^{\circ} \mathrm{C}$ down to $-70{ }^{\circ} \mathrm{C}$ at a rate of $0.7^{\circ} \mathrm{C} \mathrm{min}^{-1}$;

- Heating from $-70{ }^{\circ} \mathrm{C}$ up to $\mathrm{T}$, at a rate of $0.7{ }^{\circ} \mathrm{C} \min ^{-1}\left(-30{ }^{\circ} \mathrm{C} \leq \mathrm{T} \leq-20^{\circ} \mathrm{C}\right)$;

- Cooling from $\mathrm{T}$ down to $-70{ }^{\circ} \mathrm{C}$ at a rate of $0.7{ }^{\circ} \mathrm{C} \mathrm{min}{ }^{-1}$ and

- Final heating from $-70{ }^{\circ} \mathrm{C}$ up to $25^{\circ} \mathrm{C}$ at a rate of $0.7^{\circ} \mathrm{C} \mathrm{min}^{-1}$.

A slow rate of $0.7{ }^{\circ} \mathrm{C} \mathrm{min}{ }^{-1}$ was chosen to allow for continuous thermal equilibrium inside the sealed DSC cell. A total of 11 thermograms was acquired for each sample.

True skeleton densities $\left(\rho_{S}\right)$ of the aerogels were indirectly determined from the respective bulk densities $\left(\rho_{B}\right)$ of the samples and their porosity, as measured by helium gas pycnometry (Micromeritics Accupyc II 1340). He pycnometry $\left(27^{\circ} \mathrm{C}\right)$ was conducted 400 times per sample and the values were checked for stability (Incertitudes $<0.3 \%$ ).

Nitrogen adsorption/desorption isotherms were recorded at $77 \mathrm{~K}$ on a Quantachrome Autosorb1 instrument. All samples were degassed in vacuum prior to analysis. Specific surface areas were calculated from 11-point measurements using the Brunauer, Emmett and Teller (BET) equation.

\section{Results and discussion}

Impact of solvent on shrinkage and bulk density

The dimensional stability of cellulosic lyogels and aerogels along their preparation path and during storage depends on their solid content (which in turn mainly depends on the cellulose concentration of the respective solution), the particular cellulose aggregate structure (depending on the phase separation mechanism leading to cellulose coagulation) and the presence of hydrophilic cellulose solvent remnants, confined in fibrillary interstices of the lyogel or attached to cellulose. Traces of NMMO, for example, can result in adsorption and condensation of considerable amounts of water, which would inevitably lead to pore collapsing and shrinkage during $\mathrm{scCO}_{2}$ drying and sample storage (Liebner et al. 2009). Similarly, the derivatization of the reducing ends of cellulose by 1,3-dialkyl- $1 H$-imidazolium ionic liquids will introduce hydrophilic functions as well, which might translate into modified bulk properties (Ebner et al. 2008).

The bulk density was found to be $30-40 \mathrm{mg} \mathrm{cm}^{-3}$ for aerogels derived from $1.5 \mathrm{w} \%$ solutions of $\mathrm{CL}$ and $55-67 \mathrm{mg} \mathrm{cm}^{-3}$ for $3 \mathrm{w} \%$ solutions. The observed variances within the two density levels are due to different shrinkage values caused by the mechanisms of cellulose coagulation associated to the respective cellulose solvents ( $c f$. Morphology). The extent of shrinkage observed during the cellulose coagulation and solvent exchange (lyogel stage), as well as $\mathrm{scCO}_{2}$ drying steps (aerogel stage) is listed in Table 1.

Generally, a higher cellulose concentration (2-3 w\%) resulted in a total shrinkage of about $30-35 \%$, independently of the solvent system. However, the contributions of the individual preparation steps varied strongly. For the CL-CTO system, volume-loss was highest at the lyogel formation stage (17-24\%) for both of the studied density levels. Since visually no shrinkage was observed during coagulation, it can be attributed to the solvent exchange, most likely the transfer from ethanol $96 \mathrm{v} \%$ to water. In accordance with an earlier study on CTO-derived cellulose aerogels (Hoepfner et al. 2008), surprisingly good volumetric preservation of the gels during $\mathrm{scCO}_{2}$ drying was observed (7-10\% shrinkage only). CLEMIm and CL-NMMO aerogels prepared from $3 \mathrm{w} \%$ solutions of $\mathrm{CL}$ exhibited the opposite behavior: volume loss was low in the lyogel stage (9-11\%), but comparatively high during drying (24-26\%). The differences regarding shrinkage during $\mathrm{scCO}_{2}$ drying were particularly distinct for samples derived from low concentrations of CL $(1.5 \mathrm{w} \%)$ : the sixfold shrinkage $(42 \%)$ was observed for largely (or entirely) amorphous CL-EMIm aerogels (cellulose II crystallinity $0-15 \%$ ), when compared to CL-CTO samples (cellulose II crystallinity 46-50 \%). However, as apparent from the results of compression testing ( $c f$. Mechanical properties), differences in sample stability cannot be correlated exclusively to the crystallinity of the respective cellulose II networks, but are also strongly controlled by morphological features on nano- and microscale.

\section{Morphology}

To visualize the internal surface morphology of the prepared aerogels largely free of structural artefacts 
Table 1 Bulk density $\left(\rho_{B}\right)$ and shrinkage during coagulation, solvent exchange $\left(\mathrm{S}_{\text {coag/exch }}\right)$ and $\mathrm{scCO}_{2}$ drying $\left(\mathrm{S}_{\mathrm{dry}}\right)$ steps and total shrinkage $\left(\mathrm{S}_{\mathrm{tot}}\right)$ of aerogels derived from solutions of cotton linters (CL) in TBAF/DMSO (CL-TBAF), [EMI$\mathrm{m}][\mathrm{OAc}] / \mathrm{DMSO}$ (CL-EMIm), NMMO- $\mathrm{H}_{2} \mathrm{O}$ (CL-NMMO) and $\mathrm{Ca}(\mathrm{SCN})_{2} \cdot 8 \mathrm{H}_{2} \mathrm{O} / \mathrm{LiCl}(\mathrm{CL}-\mathrm{CTO})$

\begin{tabular}{lllllll}
\hline Sample name & CL-TBAF & CL-EMIm & CL-EMIm & CL-NMMO & CL-CTO & CL-CTO \\
\hline CL $(\mathrm{w} \%)$ & 3.0 & 1.5 & 3.0 & 3.0 & 1.5 & 2.0 \\
$\rho_{\mathrm{B}}\left(\mathrm{mg} \mathrm{cm}^{-3}\right)$ & $67.1 \pm 3.3(7)$ & $40.2 \pm 3.5(7)$ & $55.3 \pm 1.4(5)$ & $62.9 \pm 3.0(9)$ & $29.9 \pm 0.8(7)$ & $48.2 \pm 2.7(6)$ \\
$\mathrm{S}_{\text {coag/exch }}(\%)$ & $20 \pm 4(7)$ & $18 \pm 7(7)$ & $9 \pm 6(5)$ & $11 \pm 5(9)$ & $17 \pm 2(7)$ & $24 \pm 3(6)$ \\
$\mathrm{S}_{\text {dry }}(\%)$ & $19 \pm 3(7)$ & $42 \pm 2(7)$ & $26 \pm 3(5)$ & $24 \pm 3(9)$ & $7 \pm 2(7)$ & $10 \pm 2(6)$ \\
$\mathrm{S}_{\text {tot }}(\%)$ & $35 \pm 5(7)$ & $52 \pm 5(7)$ & $33 \pm 6(5)$ & $33 \pm 2(9)$ & $23 \pm 3(7)$ & $31 \pm 4(6)$ \\
\hline
\end{tabular}

The respective number of samples is given in brackets

arising from opening the samples, we cut the cylinders to a certain depth with a razor blade and thereafter carefully exposed a small piece of the aerogel body. The ripping edge of this sample was then sputtercoated with gold and analyzed by SEM (Fig. 1).

Depending on the respective solvent system, molecular disperse cellulose solutions can undergo phase separation upon standing, cooling, solidification, or addition of a cellulose antisolvent following different mechanisms. The morphology of the obtained aerogels is strongly influenced by these processes, as demonstrated by SEM in earlier studies for the cellulose solvent systems NMMO $\mathrm{H}_{2} \mathrm{O}$, [EMIm][OAc], [BMIm][Cl], and aqueous $\mathrm{NaOH}$. This has been confirmed by the current study which extended the set of studied cellulose solvent systems to TBAF/DMSO and $\mathrm{Ca}(\mathrm{SCN})_{2} \cdot 8 \mathrm{H}_{2} \mathrm{O} / \mathrm{LiCl}$. Different from earlier studies that were mainly based on lowmolecular $\left(\mathrm{M}_{\mathrm{W}} 29.2 \mathrm{~kg} \mathrm{~mol}^{-1}\right)$, microcrystalline cellulose (Gavillon and Budtova 2008; Sescousse et al. 2011), this study employed non-degraded plant cellulose (cotton linters) of considerably higher molecular weight $\left(\mathrm{M}_{\mathrm{W}} 133.5 \mathrm{~kg} \mathrm{~mol}^{-1}\right)$. Beyond that, an investigation of the solid network morphology of the coagulated cellulose by SAXS, WAXS, and solid-state NMR spectroscopy was included.

Coagulation of cellulose from [EMIm][OAc]/ DMSO yields networks of short nanofibers which assemble to globular superstructures, as illustrated in Fig. 1 (CL-EMIm). This morphology is assumed to be the result of a spontaneous one-step phase separation resembling spinodal decomposition, a mechanism which has been proposed for the coagulation of cellulose from respective solutions in [EMIm][OAc] or molten NMMO, both leading to networks of loosely agglomerated cellulose spheres (Gavillon and Budtova 2008; Sescousse et al. 2011). In case of TBAF/ DMSO, the same mechanism of diffusion-controlled coagulation and gel formation, mediated through gradual replacement of fluoride anions by water (hydrated hydroxide ions) and increasing hydrogen bonding (Östlund et al. 2009), results in dense networks of very small interwoven nanofibers (CLTBAF), and interconnected nanopore systems, which was confirmed by the small fibril and pore radii determined by SAXS and thermoporosimetry, respectively for this sample. The surface of ripping edge had a very flat appearance and could be regarded highly homogeneous, except for the high aspect ratio voids having a longitudinal dimension in the single-digit micrometer range. These fractures are likely caused by tensions affecting the cellulose network during coagulation and are reflected by a bimodal pore size distribution centered at 36 and $101 \mathrm{~nm}$ as determined by thermoporosimetry. In general solutions in TBAF and EMIm allow for the preparation of largely amorphous aerogels.

In contrast, SEM analysis of aerogels from solutions of cotton linters in NMMO $\cdot \mathrm{H}_{2} \mathrm{O}$ (CL-NMMO) or $\mathrm{Ca}(\mathrm{SCN})_{2} \cdot 8 \mathrm{H}_{2} \mathrm{O} / \mathrm{LiCl}$ (CL-CTO) revealed rather random networks of cellulose nanofibrils. For melts of the NMMO and CTO solvent systems phase separation occurs in two steps. Already during cooling of the melt to room temperature, microphase separation of free and bound solvent, accompanied by cellulose alignment to larger nanofibrils, sets in. While the free solvent is easily removed upon addition of a suitable cellulose antisolvent, contact of the antisolvent with bound solvent causes additional cellulose coagulation, which happens in close proximity to the 

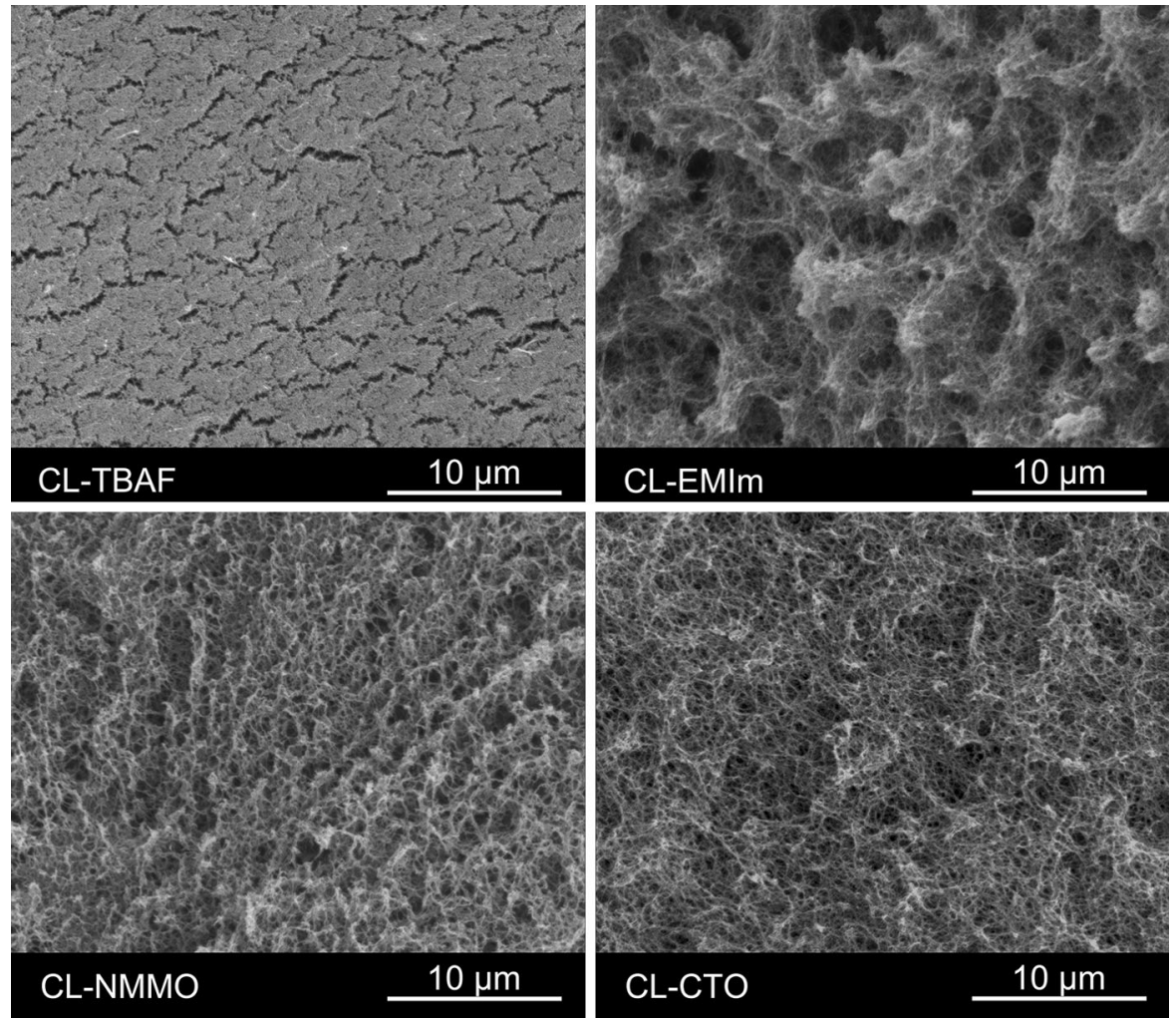

Fig. 1 Scanning electron micrographs of aerogels derived from solutions of $3.0 \mathrm{w} \%$ cotton linters in TBAF/DMSO (CL-TBAF), $[\mathrm{EMIm}][\mathrm{OAc}] / \mathrm{DMSO}(\mathrm{CL}-\mathrm{EMIm}), \mathrm{NMMO} \cdot \mathrm{H} 2 \mathrm{O}(\mathrm{CL}-\mathrm{NMMO})$ and $1.5 \mathrm{w} \%$ cotton linters in $\mathrm{Ca}(\mathrm{SCN})_{2} \cdot 8 \mathrm{H}_{2} \mathrm{O} / \mathrm{LiCl}(\mathrm{CL}-\mathrm{CTO})$

ordered cellulose domains formed during primary phase separation (Gavillon and Budtova 2008; Hoepfner et al. 2008). The comparatively slow phase separation seems to enable better orientation and assembling of cellulose as evident from the high cellulose II crystallinities of CL-CTO aerogels ( $c f$. Solid characteristics) which is supposedly the main reason for the surprisingly low shrinkage of CTOderived gels during conversion to aerogels. The relatively strong shrinkage of CL-NMMO samples (comparable with CL-EMIm) is assumed to be due to the particular solidification behavior of Lyocell dopes containing less than $6 \mathrm{w} \%$ of cellulose. Below $30^{\circ} \mathrm{C}$, NMMO of low cellulose content contracts significantly (Liu et al. 2001), which inevitably leads to cracks and voids inside the final aerogel bodies (Schimper et al. 2011).

Mechanical properties

The response of cellulosic aerogels towards compressive stress corresponds to Gibson and Ashbys
Mechanics of three-dimensional cellular materials (Gibson and Ashby 1982) and has previously been discussed e.g. for bacterial cellulose aerogels (Liebner et al. 2012a). While the same general response regions can be assigned to all samples analyzed in this work, it is evident that the specific curve progression is significantly influenced by the applied solvent systems (Fig. 2a). For CL-TBAF, CL-NMMO and CL-CTO aerogels, a strong stress increase in the region of linear elastic deformation at low compressive strain entails higher elastic moduli ( $\left.E_{\text {compr }}\right)$, hence rigidity, compared to aerogels derived from solutions of $\mathrm{CL}$ in [EMIm][OAc]/DMSO (CL-EMIm). In contrast to the uniform nanostructure of CL-TBAF aerogels and the ordered crystalline fibrillary networks of CL-NMMO and CL-CTO, the comparatively heterogeneous morphology of CL-EMIm aerogels renders them very ductile.

When cell wall buckling [referring to the model introduced by Gibson and Ashby (1982)], hence nonlinear elastic deformation of the aerogel sets in, the slope of the curves flattens to a certain extent. The 


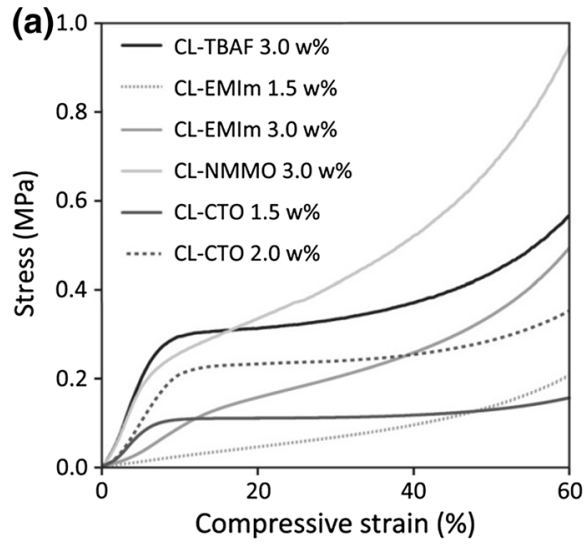

Fig. 2 Compression tests: stress-strain curves (a) and specific moduli (b) of aerogels derived from solutions of cotton linters in TBAF/DMSO (CL-TBAF), [EMIm][OAc]/DMSO (CL-

following plateau region between about 15 and $40 \%$ strain indicates progressing plastic deformation due to cell collapsing (Gibson and Ashby 1982). The response profiles of CL-TBAF and CL-CTO aerogels show very distinct plateau regions, where energy is absorbed by the materials without a considerable increase in stress. In case of CL-EMIm and CLNMMO aerogels, the stress gradually increases, indicating a higher load-bearing capacity during plastic deformation.

To account for the strong dependency of the mechanical properties of cellulosic aerogels on even small differences in their bulk density, respective density-normalized specific moduli and yield strength values (Table 2) have been calculated, which are more suitable to compare the lightweight samples prepared in this study differing in both structure and solid content.

Cellulose aerogel networks containing a higher amount of ordered domains (CL-NMMO and CLCTO aerogels) had similar specific moduli of 67-68 MPa cm $\mathrm{g}^{-1}$ (Fig. 2b). In contrast, the largely amorphous CL-TBAF and CL-EMIm aerogels showed significant differences in their rigidity. While the rather uniform morphology, fine fibrils and small pore size of CL-TBAF resulted in a brittle structure (which also explains the very smooth ripping edge observed upon SEM analysis) that proved to be very rigid under compressive stress, the open and more heterogeneous cellulose II network of CL-EMIm aerogels was very ductile compared to all other

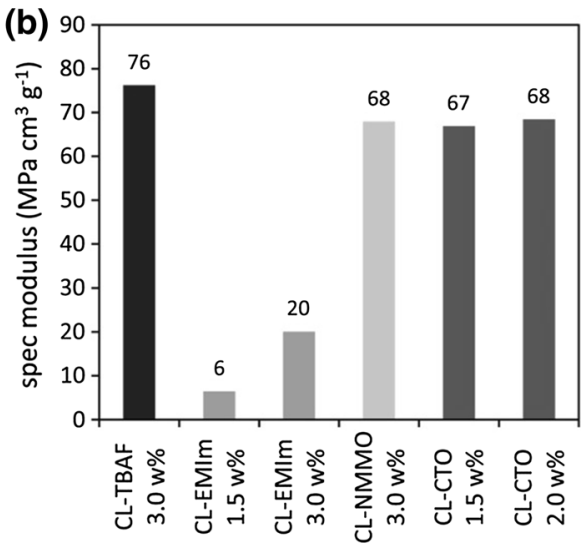

EMIm), NMMO $\cdot \mathrm{H}_{2} \mathrm{O}$ [CL-NMMO, data obtained from (Liebner et al. 2009)] and $\mathrm{Ca}(\mathrm{SCN})_{2} \cdot 8 \mathrm{H}_{2} \mathrm{O} / \mathrm{LiCl}(\mathrm{CL}-\mathrm{CTO})$

materials and showed a strong density-dependency compared to CL-CTO aerogels. The stress at which plastic deformation sets in (yield strength) shows similar trends, but a higher density dependency for both amorphous CL-EMIm as well as crystalline CLCTO specimen (Table 2).

\section{Solid characteristics}

\section{Crystallinity and solid state structure}

Solid state NMR analysis of the cellulosic raw material (cotton linters), gave a cellulose I crystallinity index of $68 \%$. Aerogels derived from all four solvent systems exhibited—if at all—exclusively cellulose II crystallinity.

Coagulation of cellulose from solutions in TBAF or EMIm occurs by spinodal decomposition. This describes a spontaneous phase separation mechanism solely driven by diffusion which separates a solution of two or more components into distinct regions (or phases) that distinctly differ in both chemical composition and physical properties. The spontaneous materialization of a periodic variation of composition with distance as described by the Cahn-Hillard equation is assumed to be main reason for the low cellulose II crystallinities of samples CL-TBAF and CL-EMIm. Crystallinity for these samples was only indicative from the WAXS experiments $(\leq 15 \%$; $c f$. Table 3$)$ while NMR results suggest the absence of any cellulose II crystallinity. The patterns of small- and wide-angle 
Table 2 Mechanical properties under compressive stress: Young's modulus $(E)$, specific modulus $\left(E_{\rho}\right)$, yield strength $(\sigma)$ and specific yield strength $\left(\sigma_{\rho}\right)$ of aerogels derived from solutions of cotton linters in TBAF/DMSO (CL-TBAF), $\left[\right.$ EMIm] $[\mathrm{OAc}] / \mathrm{DMSO}$ (CL-EMIm), NMMO- $\mathrm{H}_{2} \mathrm{O}$ (CL$\mathrm{NMMO})$ and $\mathrm{Ca}(\mathrm{SCN})_{2} \cdot 8 \mathrm{H}_{2} \mathrm{O} / \mathrm{LiCl}(\mathrm{CL}-\mathrm{CTO})$

\begin{tabular}{lllllll}
\hline Sample name & CL-TBAF & CL-EMIm & CL- EMIm $^{\text {a }}$ & CL-NMMO $^{\text {b }}$ & CL-CTO $^{\mathrm{a}}$ & CL-CTO \\
\hline CL $(\mathrm{w} \%)$ & 3.0 & 1.5 & 3.0 & 3.0 & 1.5 & 2.0 \\
$E(\mathrm{MPa})$ & $5.12 \pm 1.48(7)$ & $0.26 \pm 0.02(6)$ & $1.12 \pm 0.21(5)$ & 4.26 & $2.00 \pm 0.07(5)$ & $3.30 \pm 0.63(5)$ \\
$E_{\rho}\left(\mathrm{MPa} \mathrm{cm} \mathrm{g}^{-1}\right)$ & 76 & 6 & 20 & 68 & 67 & 68 \\
$\sigma(\mathrm{kPa})$ & $240 \pm 14(7)$ & $22 \pm 4(6)$ & $115 \pm 11(5)$ & 184 & $76 \pm 2(5)$ & $160 \pm 23(5)$ \\
$\sigma_{\rho}\left(\mathrm{MPa} \mathrm{cm} \mathrm{g}^{-1}\right)$ & 3.6 & 0.5 & 2.1 & 2.9 & 2.6 & 3.3 \\
\hline
\end{tabular}

The respective number of samples is given in brackets

${ }^{\text {a }}$ Data obtained from Pircher et al. (2015)

b Data obtained from Liebner et al. (2009)

Table 3 Cellulose II crystallinity, cylinder radius $\left(\mathrm{R}_{\mathrm{c}}\right)$, porod exponent $(\mathrm{PE})$ and skeletal density $\left(\rho_{\mathrm{S}}\right)$ of aerogels derived from solutions of cotton linters (CL) in TBAF/DMSO (CL-
TBAF), [EMIm][OAc]/DMSO (CL-EMIm), NMMO $\mathrm{H}_{2} \mathrm{O}$ $(\mathrm{CL}-\mathrm{NMMO})$ and $\mathrm{Ca}(\mathrm{SCN})_{2} \cdot 8 \mathrm{H}_{2} \mathrm{O} / \mathrm{LiCl}(\mathrm{CL}-\mathrm{CTO})$

\begin{tabular}{lllll}
\hline Sample name & CL-TBAF & CL-EMIm & CL-NMMO & CL-CTO \\
\hline CL (w\%) & 3.0 & 3.0 & 3.0 & 1.5 \\
Crystallinity (WAXS) & 15 & 13 & 24 & 46 \\
Crystallinity (NMR) & 0 & 0 & 27 & 50 \\
$\mathrm{R}_{\mathrm{c}}$ SAXS (nm) & $4.0 \pm 0.1$ & $4.3 \pm 0.1$ & $4.5 \pm 0.1$ & $4.5 \pm 0.1$ \\
PE & 1.9 & 1.9 & 2.4 & 3.0 \\
$\rho_{\mathrm{S}}\left(\mathrm{g} \mathrm{cm}^{-3}\right)$ & $1.529 \pm 0.002$ & $1.527 \pm 0.002$ & $1.531 \pm 0.002$ & $1.543 \pm 0.001$ \\
\hline
\end{tabular}

X-ray scattering shown in Fig. 3 furthermore reveal higher cellulose II crystallinity for the aerogel samples CL-NMMO and CL-CTO whose cellulose networks had been formed by (1) micro phase separation of free and bound solvent fractions and (2) subsequent removal of both phases by a cellulose anti-solvent. This is most likely due to the comparatively slow first step that better allows for the formation of ordered cellulose domains. However, despite the concordant results of X-ray scattering and solid-state NMR, the comparatively low cellulose II crystallinity of CL-NMMO has to be treated with care as the respective WAXS diffractogram is equivalent to that of ball-milled cellulose (Nam et al. 2016) that can be fitted with a $9^{\circ}$ pwhm cellulose II pattern and that corresponds to a crystallite size (Scherrer formula) of just a couple of cellulose chains, i.e. not a crystal in most views. Thus, CL-CTO can be regarded the only type of aerogel in this study that has considerable cellulose II crystallinity. Calculation of WAXS crystallinity using a different position, such as that at $11 \mathrm{~nm}^{-1}$ results in somewhat higher crystallinity values which diverge more from NMR crystallinities, however, without altering the afore-discussed trend amongst the different types of aerogels.

Pre-cooled aqueous solutions of alkali hydroxides represent another type of cellulose solvent that has recently been investigated for the preparation of aerogels. Similar as with $\mathrm{NMMO} \cdot \mathrm{H}_{2} \mathrm{O}$ or molten $\mathrm{Ca}(\mathrm{SCN})_{2} \cdot 8 \mathrm{H}_{2} \mathrm{O}$, phase separation occurs in two steps, affording cellulose II fibril networks of considerable crystallinity. Dissolution of cotton linters (74\% cellulose I crystallinity), for example, in an aqueous solution of $6 \mathrm{w} \% \mathrm{NaOH}$ and $4 \mathrm{w} \%$ urea (pre-cooled and slurried at $4{ }^{\circ} \mathrm{C}$, dissolution at $-5^{\circ} \mathrm{C}$ for $5 \mathrm{~h}$ ), followed by cellulose coagulation with $2 \% \mathrm{H}_{2} \mathrm{SO}_{4}$ and exhaustive washing, resulted in a cellulose II crystallinity of $51 \%$ (Zhang et al. 2001), which is comparable to that of the CL-CTO samples.

The skeletal or true density $\left(\rho_{\mathrm{S}}\right)$ of all prepared aerogels was between 1.527 and $1.543 \mathrm{~g} \mathrm{~cm}^{-3}$ and 


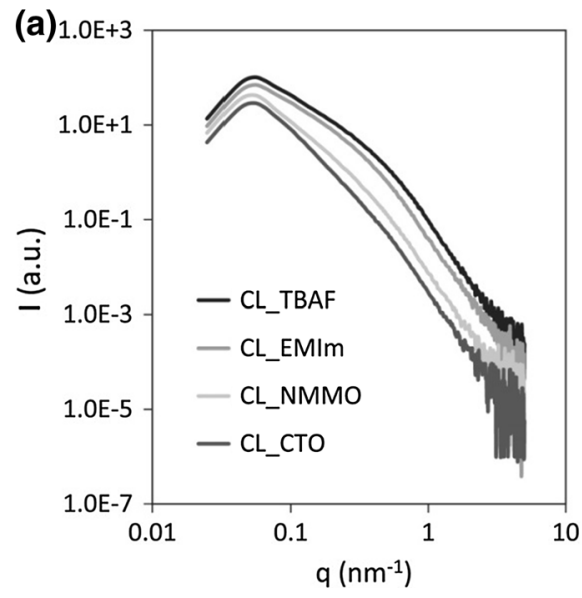

Fig. 3 SAXS (a) and WAXS (b) patterns of aerogels derived from solutions of $3.0 \mathrm{w} \%$ cotton linters in TBAF/DMSO (CLTBAF), [EMIm] [OAc]/DMSO (CL-EMIm), NMMO- $\mathrm{H}_{2} \mathrm{O}$ (CL$\mathrm{NMMO})$ and $1.5 \mathrm{w} \%$ cotton linters in $\mathrm{Ca}(\mathrm{SCN})_{2} \cdot 8 \mathrm{H}_{2} \mathrm{O} / \mathrm{LiCl}$

increased with cellulose crystallinity (Table 3 ). In native cellulose, the density of a perfect crystal is 1.582 (cellulose $\mathrm{I} \alpha$ ) and $1.599 \mathrm{~g} \mathrm{~cm}^{-3}$ (cellulose $\mathrm{I} \beta$ ), respectively (Sugiyama et al. 1991). With an increasing amount of amorphous regions, hence less dense packing of cellulose molecules, the skeletal density of cellulose microfibrils decreases. Commercially available microcrystalline cellulose, such as Avicel ${ }^{\circledR} \mathrm{PH}-$ 102 (cellulose I crystallinity $>70 \%$ ), for example, has a true density of around $1.58 \mathrm{~g} \mathrm{~cm}^{-3}$ (Kumar et al. 2002; Rojas et al. 2011).

The size of the network-forming cellulose particles was determined by SAXS. Due to the fact that linear cellulose molecules aggregate into fibrillar entities, we generally assumed elongated fibrillary structures building up the solid aerogel matrices. Therefore the evaluation approach proposed by Jeong et al. (2005) for fibrillary structures, corresponding to cylinders longer than the low-q range of the SAXS measurement, was applied. The cylinder radius $R_{c}$ was calculated by a modified Guinier fit yielding a radius of gyration $R_{g}$ which is related to $R_{c}$ by $R_{c}=\sqrt{2} R_{g}$. It was found that the mean radius of the cellulose fibrils was $4.0-4.5 \mathrm{~nm}$ for all aerogels investigated, but smallest for aerogels derived from solutions of CL in TBAF/DMSO (CL-TBAF), which showed a comparatively homogeneous and dense cellulose nanofibril structure ( $c f$. Morphology) and the highest rigidity ( $c f$. Mechanical properties) as well as surface area compared to the other samples.

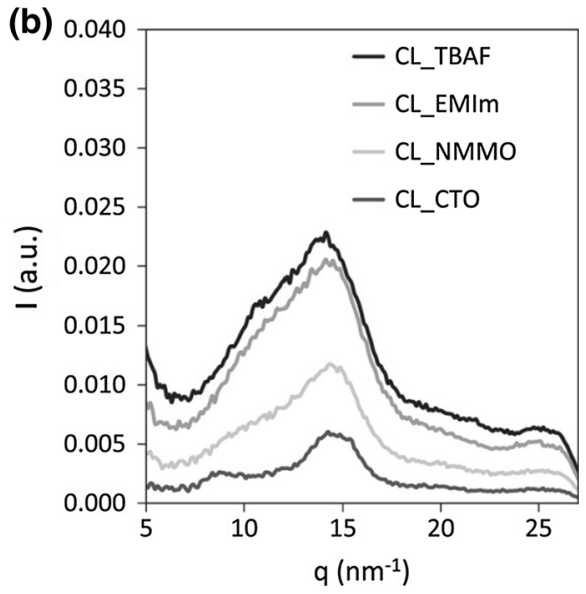

(CL-CTO). Note that the intensity is in arbitrary units and does not reflect the degree of crystallinity, which is determined by the ratio of crystalline to amorphous signals

From the obtained SAXS patterns (Fig. 3a) and the Porod exponent (PE) related to the fractal dimension, in both low and high q-range, the Porod regime can be determined (Ruland 2001) following the relation $\mathrm{I}(\mathrm{Q}) \sim \mathrm{q}^{(-\mathrm{PE})}$, where $1<(\mathrm{PE})<3$ is attributed to mass fractals and $3<(\mathrm{PE})<4$ to surface fractals. Mass fractals are usually found for interlinked chains $(\mathrm{PE}=2)$ or clustered networks $(\mathrm{PE}=3)$, while surface fractals are attributed to rough surfaces $(\mathrm{PE}=3)$ or smooth surfaces $(\mathrm{PE}=4)$. According to the exponent of the scattering curve in the low q-range the aerogel samples CL-TBAF, CL-EMIm and CL-NMMO were characterized as mass fractals, rather interlinked chains, whereas the high value of the samples CL-CTO distinguished the sample as either a clustered network or a rough surface fractal. Furthermore a PE value towards 3 can be interpreted as related to a 3D-branched structure.

For CL-NMMO and CL-CTO aerogels, a higher value of $\mathrm{R}_{\mathrm{c}}$, together with the increased skeletal density and crystallinity values, corresponds with the good dimensional and mechanical stability and somewhat lower inner surface areas. Especially CL-CTO aerogels (cellulose II crystallinity 46-50\%) tend towards a more compact, 3D-branched structure as shown by PE, which most likely contributes also to the comparable high specific modulus $\left(E_{\rho}\right)$. In contrast, the ductile CL-EMIm aerogels feature a smaller value of $\mathrm{R}_{\mathrm{c}}$, low crystallinity (13\%) and a lower PE pointing towards 2-dimensional fractal agglomerates with rougher surfaces. 
Taking the measured porosity values (Table 5) into account, the fractions $\phi_{1}$ and $\phi_{2}=1-\phi_{1}$ could be calculated for the aerogels which allowed the determination of the inner surface area-to-volume ratio of pores $(\mathrm{S} / \mathrm{V})$ by $\mathrm{SAXS}$ in addition to the $\mathrm{SA}_{\mathrm{V}}$ parameter derived from the $\mathrm{N}_{2}$ adsorption/desorption experiments (Table 4). The S/V and SAv values show the same trend while they differ by factors of $4-5$. The reason for the observed differences is not yet clear, cannot be explained solely by the fact that SAXS includes the surface of closed pores as well, and will be subject of further investigations. The loose packing of the cellulose fibrils in highly amorphous CL-TBAF and CL-EMIm aerogels resulted in increased specific surface areas (SSA) as well as surface area-to-volume ratios $\left(\mathrm{SA}_{\mathrm{V}}\right)$. The nanostructured fibril network of the TBAF/DMSO derived sample $\left(\mathrm{R}_{\mathrm{c}}=4.0 \mathrm{~nm}\right)$ exhibited the highest SSA of $328 \mathrm{~m}^{2} \mathrm{~g}^{-1}$. Conversely, the tight packing of the ordered structures in CL-CTO aerogels resulted in decreased accessible surface areas. The low SAV of CL-CTO $\left(5.7 \mathrm{~m}^{2} \mathrm{~cm}^{-3}\right)$ is furthermore a consequence of the low cellulose concentration of the respective $\mathrm{Ca}(\mathrm{SCN})_{2} \cdot 8 \mathrm{H}_{2} \mathrm{O} / \mathrm{LiCl}$ solution $(1.5 \mathrm{w} \%)$ and can therefore not directly compared with the SAV values of the other samples as pore size and pore walls may change as a function of cellulose concentration using the same solvent.

\section{Molar mass distribution}

Cellulose integrity strongly depended on the respective dissolution method (Fig. 4). The weight average molecular weight $\left(\mathrm{M}_{\mathrm{w}}\right)$ of CL-TBAF and CL-EMIm aerogels was hardly affected compared to the starting

Table 4 Specific surface area (SSA), surface area-to-volume ratio $\left(\mathrm{SA}_{\mathrm{V}}\right)$ and $\mathrm{C}$ constant obtained by nitrogen sorption experiments at $77 \mathrm{~K}$ and inner surface area-to-volume ratio (S/ V) from SAXS of aerogels derived from solutions of cotton material (cotton linters, CL). Both solvents had been applied at comparatively low temperatures of $60{ }^{\circ} \mathrm{C}$ (CL-TBAF) and room temperature (CL-EMIm). In contrast, the $\mathrm{M}_{\mathrm{w}}$ of CL-NMMO (dissolution at $\left.110{ }^{\circ} \mathrm{C}\right)$ and CL-CTO $\left(140{ }^{\circ} \mathrm{C}\right)$ were 24 and $39 \%$, respectively, below the $\mathrm{M}_{\mathrm{w}}$ of CL.

Regarding solutions of CL in NMMO, a previous study showed that the shift of the distribution towards lower molecular weights is connected to the formation of new carbonyl groups, indicating that the main degradation mechanism in stabilized Lyocell dopes is beta-alkoxy elimination (Liebner et al. 2009). Kuga

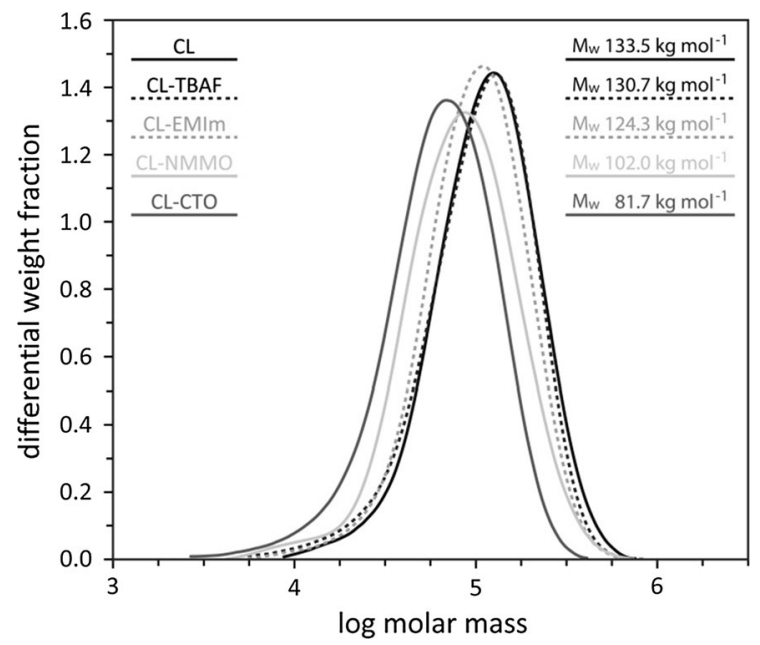

Fig. 4 Molecular weight distribution and weight average molecular weight $(\mathrm{Mw})$ of the starting material $(C L$ cotton linters) and aerogels derived from solutions of CL in TBAF/ DMSO (CL-TBAF), [EMIm][OAc]/DMSO (CL-EMIm), $\mathrm{NMMO} \cdot \mathrm{H}_{2} \mathrm{O}(\mathrm{CL}-\mathrm{NMMO})$ and $\mathrm{Ca}(\mathrm{SCN})_{2} \cdot 8 \mathrm{H}_{2} \mathrm{O} / \mathrm{LiCl}$ (CLCTO)

linters (CL) in TBAF/DMSO (CL-TBAF), [EMIm][OAc]/ DMSO (CL-EMIm), NMMO- $\mathrm{H}_{2} \mathrm{O}$ (CL-NMMO) and $\mathrm{Ca}(\mathrm{SCN})_{2} \cdot 8 \mathrm{H}_{2} \mathrm{O} / \mathrm{LiCl}(\mathrm{CL}-\mathrm{CTO})$

\begin{tabular}{lllll}
\hline Sample name & CL-TBAF & CL-EMIm & CL-NMMO & CL-CTO \\
\hline CL $(\mathrm{w} \%)$ & 3.0 & 3.0 & 3.0 & 1.5 \\
SSA $\left(\mathrm{m}^{2} \mathrm{~g}^{-1}\right)$ & $328 \pm 1(10)$ & $246 \pm 2(5)$ & $250 \pm 10^{\mathrm{a}}$ & $190 \pm 4(5)$ \\
$\mathrm{SA}_{\mathrm{V}}\left(\mathrm{m}^{2} \mathrm{~cm}^{-3}\right)$ & $22.5 \pm 0.1(10)$ & $13.7 \pm 0.1(5)$ & $15.7 \pm 0.6^{\mathrm{a}}$ & $5.7 \pm 0.1(5)$ \\
$\mathrm{C}$ & $161 \pm 6(10)$ & $165 \pm 22(5)$ & $126 \pm 10(10)$ & $125 \pm 27(5)$ \\
$\mathrm{S} / \mathrm{V}\left(\mathrm{m}^{2} \mathrm{~cm}^{-3}\right)$ & $112 \pm 1$ & $74 \pm 3$ & $74 \pm 2$ & $21.4 \pm 0.6$ \\
\hline
\end{tabular}

The respective number of samples is given in brackets

a Data obtained from Liebner et al. (2009) 
(1980) prepared cellulosic lyogels from $59 \mathrm{w} \%$ calcium thiocyanate aqueous solutions (molar ratio $\mathrm{H}_{2} \mathrm{O}: \mathrm{Ca}^{2+}=6: 1$ ) of Whatman CF-1 cellulose powder (DP 180), dissolving sulfite pulp (DP 770) and cotton linters (DP 1620) and reported a considerable loss in DP (CF-1: $6 \%$; dissolving pulp: $36 \%$; CL: $69 \%$ ). However, since the elemental composition of the coagulated cellulose samples was in agreement with that of the respective starting material, chemical derivatization of cellulose was ruled out as a possible reason for cellulose degradation, but assigned to the high input of thermal energy during dissolution (Kuga 1980).

\section{Porosity characteristics}

A thermogram obtained by thermoporosimetry for sample CL-EMIm is illustrated in Fig. 5 (and in Fig. S4 co-displayed with a thermogram of neat o-xylene; supplementary information), showing the following characteristic regions and thermal events:

- The exothermic peak observed during the first cooling step $\left(\mathrm{T}=-47^{\circ} \mathrm{C}\right)$ results from the crystallization of $o$-xylene accompanied by a supercooling phenomenon.

- When increasing the temperature from -70 up to $-25^{\circ} \mathrm{C}$, an endothermic peak in the higher temperature range indicates melting of the solvent confined in pores below about $10 \mu \mathrm{m}$ of the aerogel.

- Heating is stopped at $-25^{\circ} \mathrm{C}$, a temperature which was chosen to avoid melting of the bulk solvent (Fig. 5, Inset), and the system is slowly cooled down for a second cycle without super-cooling, as the bulk solvent already exists in solid state. The exothermic peak pattern now observed at around $\mathrm{T}=-29^{\circ} \mathrm{C}$ is solely caused by crystallization of the confined solvent. Deconvolution of the peak pattern in this range using a pseudo-Voight function with least-square refinement, and subsequent integration of the resolved peaks can provide detailed information regarding pore size distribution, their modality, and pore geometry.

- Final heating from $\mathrm{T}=-70^{\circ} \mathrm{C}$ up to room temperature causes a broad endothermic peak at approx. $22{ }^{\circ} \mathrm{C}$ associated to the melting of the bulk solvent.

The PSDs of all aerogels prepared in this study (Fig. 6) were calculated by transforming the respective thermograms, i.e. the crystallization curves acquired after heating from -70 to $-25^{\circ} \mathrm{C}$, according to Eq. (9). The margin of error of TPM measurements, arising mainly from the TPM calibration curves, ranges from 2 to $9 \%$ for macropores and is less than $5 \%$ for mesopores (Dessources et al. 2012).
Fig. 5 DSC thermogram of a CL-EMIm aerogel soaked in $o$-xylene-the crystallization curve (3) acquired after heating from -70 to $-25^{\circ} \mathrm{C}(2)$ was used to calculate the PSD. Inset selection of 11 thermograms measured on CL-EMIm aerogels, amplified in the exothermic peak (3) associated with the crystallization of the confined solvent

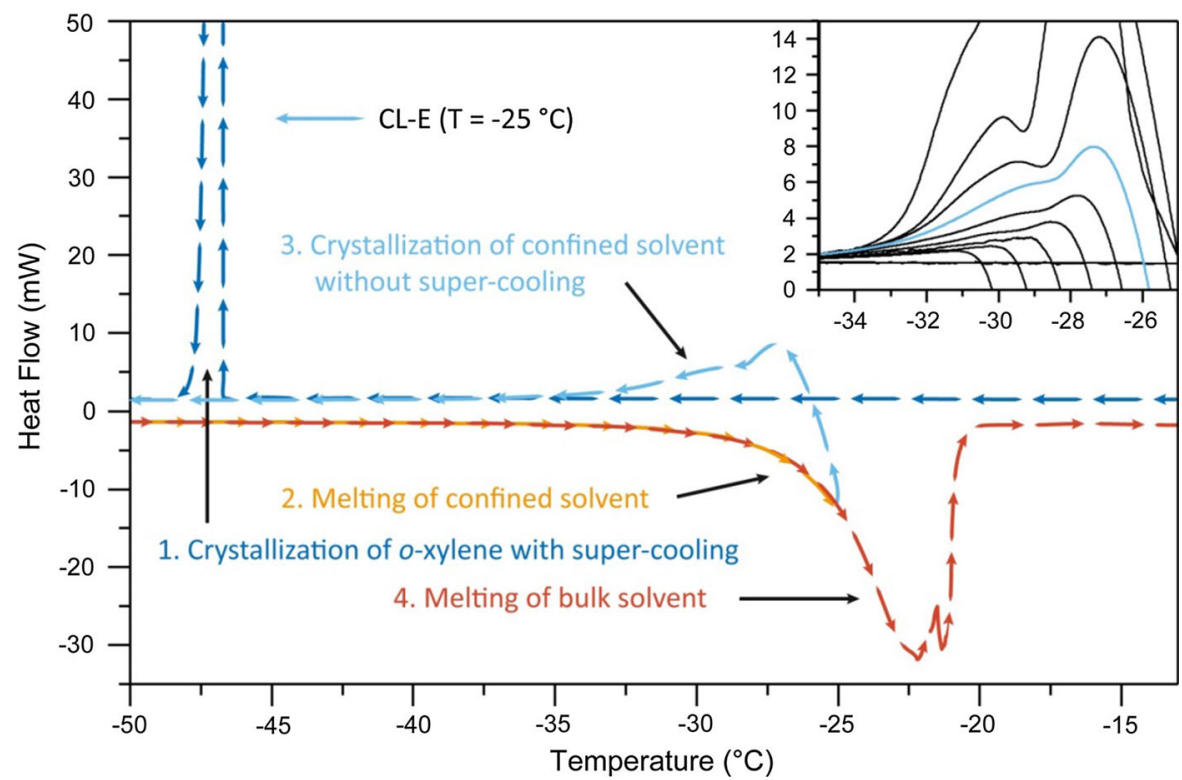


Fig. 6 Normalized pore size distribution (PSD) as obtained by TPM analysis. Aerogels have been derived from solutions of $3.0 \mathrm{w} \%$ cotton linters in TBAF/ DMSO (CL-TBAF), [EMIm] $[\mathrm{OAc}] / \mathrm{DMSO}(\mathrm{CL}-$ EMIm), NMMO $\cdot \mathrm{H}_{2} \mathrm{O}(\mathrm{CL}-$ NMMO) and $1.5 \mathrm{w} \%$ cotton linters in $\mathrm{Ca}(\mathrm{SCN})_{2} \cdot 8 \mathrm{H}_{2} \mathrm{O}$ / $\mathrm{LiCl}$ (CL-CTO). Inset Correlation between specific surface area (SSA) and peak maxima of the PSDs

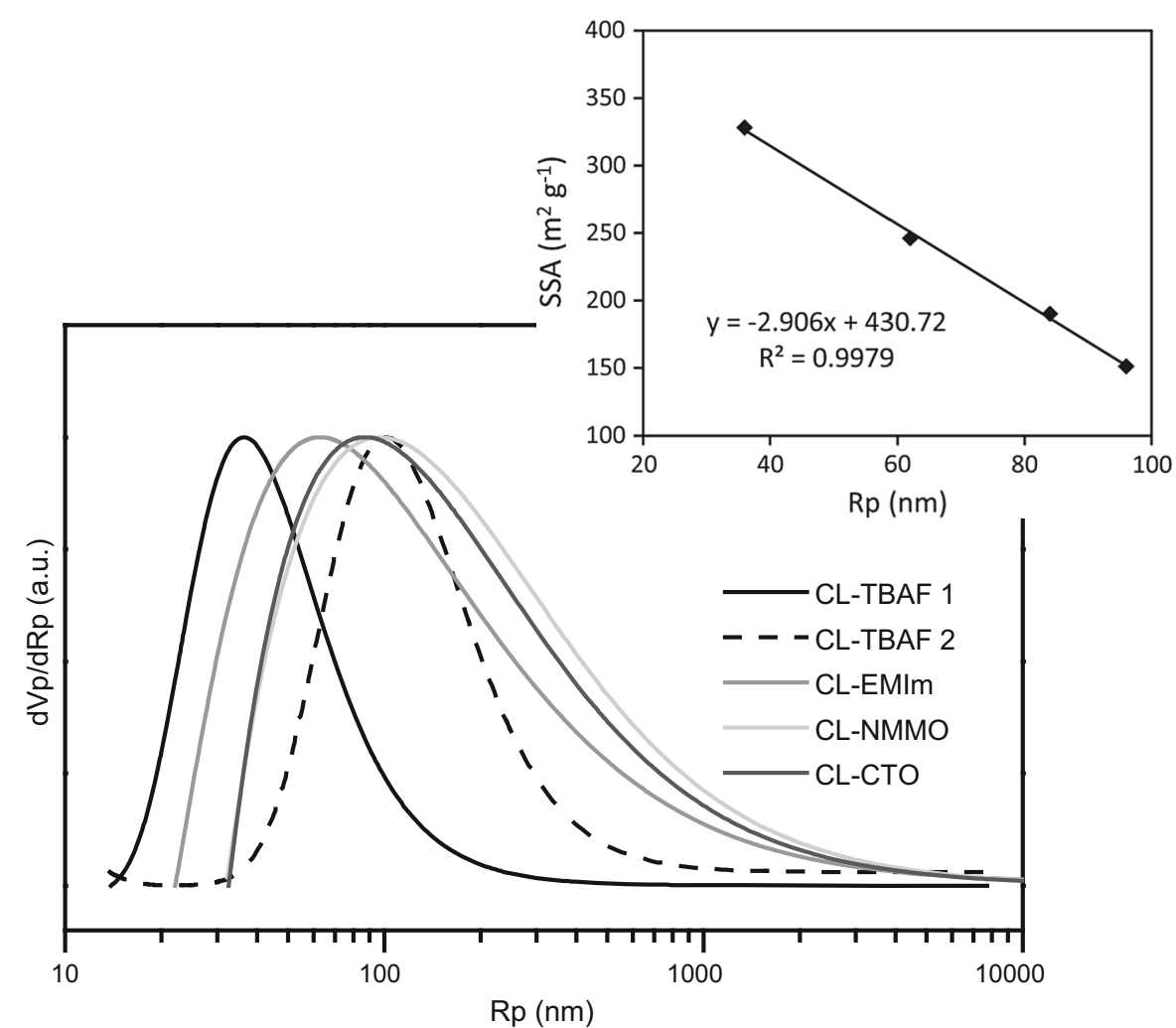

Table 5 Average pore size $(\varnothing)$ according to thermoporosimetry analysis and nitrogen sorption experiments at $77 \mathrm{~K}$, pore volume, and overall porosity as obtained by helium pycnometry for aerogels derived from solutions of cotton linters in
TBAF/DMSO (CL-TBAF), [EMIm][OAc]/DMSO (CL$\mathrm{EMIm}), \mathrm{NMMO} \cdot \mathrm{H}_{2} \mathrm{O}(\mathrm{CL}-\mathrm{NMMO})$ and $\mathrm{Ca}(\mathrm{SCN})_{2} \cdot 8 \mathrm{H}_{2} \mathrm{O} / \mathrm{LiCl}$ (CL-CTO)

\begin{tabular}{lllll}
\hline Sample name & CL-TBAF & CL-EMIm & CL-NMMO & CL-CTO \\
\hline CL (w\%) & 3.0 & 3.0 & 3.0 & 1.5 \\
Pore size TPM (nm) & $36 / 101$ & 62 & 96 & 84 \\
Modal pore size BJH (nm) & 34.5 & 34.4 & 32.1 & 2.7 \\
Hydraulic pore size $(\mathrm{nm})$ & 72.3 & 38.4 & 36.7 & 23.6 \\
Pore volume $\left(\mathrm{cm}^{-3} \mathrm{~g}^{-1}\right)$ & 5.9 & 2.4 & 1.4 & 0.8 \\
Porosity $(\%)$ & $95.5 \pm 0.1$ & $96.3 \pm 0.1$ & $95.9 \pm 0.1$ & $98.1 \pm 0.1$ \\
\hline
\end{tabular}

The structure of cellulosic aerogels consists of a cellulose fibril network and an interstitial hierarchical system of interconnected voids which often comprises more than $95 \%$ of the sample volume. Due to the random character of the fibril network, a narrow PSD is quite unlikely, especially at such low aerogel densities. Indeed, in case of the investigated cellulose II aerogels, broad PSDs have been obtained, covering pore sizes from the nano- to the micrometer range. The respective peak position of the pore radius and the curve shape showed a considerable influence of the applied solvent system. Loosely packed, amorphous aerogels were found to tend towards smaller pore sizes, especially the TBAF/DMSO derived aerogel (CL-TBAF), which, in agreement with SEM analysis (Fig. 1), had a comparatively narrow PSD with an upper limit at around $1 \mu \mathrm{m}$. CL-TBAF aerogels showed an additional larger pore fraction peaking at $101 \mathrm{~nm}$ corresponding to the cracks visible in the SEM micrographs. 
Irrespective of the type of solvent used, the specific surface area (SSA) calculated from nitrogen sorption isotherms (Fig. S1-S3, supplementary information) showed a linear negative correlation to the peak pore size of the cellulosic aerogels as determined by TPM (Fig. 6, inset). Considering the strong structural differences between the samples, the low deviation of the values from this trend is remarkable. Provided thorough calibration, this dependency could even be used to estimate the pore size of this particular type of aerogels from SSA, and vice versa.

The overall porosity was around $96 \%$ for aerogels of comparable cellulose content ( $3 \mathrm{w} \% \mathrm{CL}$ ) and $98 \%$ in case of CL-CTO (1.5 w\% CL) (Table 5).

\section{Conclusions}

The type of solvent system used to obtain solutions of cellulose has been demonstrated to have a strong impact on the nanomorphology of cellulose II aerogels derived thereof. This process encompassed (1) coagulation of the biopolymer from solution state by the cellulose antisolvent ethanol and (2) supercritical carbon dioxide extraction of ethanol from the interconnected pore system. Significant differences on the supramolecular and nanostructural level are caused by particular solvent effects and translate into aerogels of comparable density that-although prepared from the same cellulose source and similar concentrationscan considerably differ in their properties, as for example, their mechanical stability.

Significantly increased cellulose II crystallinity was found in aerogels prepared in solvents that allowed the formation of ordered domains or aggregates already prior cellulose coagulation, such as $\mathrm{Ca}(\mathrm{SCN})_{2} \cdot 8 \mathrm{H}_{2} \mathrm{O} /$ $\mathrm{LiCl}(46-50 \%)$ or NMMO· $\mathrm{H}_{2} \mathrm{O}(24-27 \%)$. SAXS analysis furthermore revealed that fibrils of 8-9 $\mathrm{nm}$ in diameter are the main particles forming the cellulose networks in coagulated cellulose. The skeletal density of the fibril aggregates increased with cellulose crystallinity, which was associated with the presence of thicker nanofibrils, imparting the respective aerogels with good mechanical properties. According to the fractal dimension of the SAXS patterns, aerogels derived from $\mathrm{Ca}(\mathrm{SCN})_{2} \cdot 8 \mathrm{H}_{2} \mathrm{O} / \mathrm{LiCl}$ solutions are the only type of cellulose II aerogels in this study which showed surface fractal characteristics indicating 3Dbranched structures. This explains the excellent mechanical and dimensional stability, but somewhat lower surface area of these aerogels. All other cellulose solvent systems afforded aerogels of mass fractal characteristics, suggesting a cellulose agglomerate structure consisting of disc-like shaped particles of less entanglement, hence poorer mechanical properties. Interestingly, aerogels derived from cellulose solutions in TBAF/DMSO deviated somewhat from all other aerogels. Regardless of their entirely amorphous cellulose structure, CL-TBAF samples featured the highest rigidity under compressive stress. It is assumed this is due to their uniform morphology, small diameter of fibrils forming the scaffold, and small size of pores hosted by the cellulose network. In accordance, the determination of the accessible surface of open pores by nitrogen sorption $\left(328 \mathrm{~m}^{2} \mathrm{~g}^{-1}\right)$ as well as of the total pore surface area by SAXS $\left(112 \mathrm{~m}^{2} \mathrm{~cm}^{-3}\right)$ revealed a comparatively high internal surface of CLTBAF aerogels. Samples which had higher crystallinities and larger nanofibril diameters (e.g. CL-CTO) generally tended towards lower surface areas. TPM which was adapted for the use on cellulose-based aerogels in course of this work, revealed broad pore size distributions which exhibited a shift of the position of the main peak (36-96 nm) towards smaller pores with increasing specific surface area of the cellulosic aerogel sample, irrespective of the applied solvent.

The results obtained in this study show:

- Thermoporosimetry is a suitable tool to determine the pore size determination of cellulose based aerogels.

- A clear relationship between solvent system, achieved structure and mechanical properties of the cellulosic aerogels.

- Careful selection of the solvent system allows tailoring cellulose II aerogel properties.

Thus this study supports the further development of cellulosic aerogels for high-performance applications, such as thermal and acoustic insulation, cell scaffolding materials for tissue engineering, or matrix materials for 3D display applications, by choosing a suitable solvent system to achieve the desired nanostructure and material properties.

Acknowledgments Open access funding provided by Austrian Science Fund (FWF). The financial support by the Austrian Science Fund (FWF: I848-N17) and the French L'Agence Nationale de la Recherché (ANR-11-IS08-0002; 
Austrian-French Project CAP-Bone) is gratefully acknowledged.

Open Access This article is distributed under the terms of the Creative Commons Attribution 4.0 International License (http:// creativecommons.org/licenses/by/4.0/), which permits unrestricted use, distribution, and reproduction in any medium, provided you give appropriate credit to the original author(s) and the source, provide a link to the Creative Commons license, and indicate if changes were made.

\section{References}

Aaltonen O, Jauhiainen O (2009) The preparation of lignocellulosic aerogels from ionic liquid solutions. Carbohydr Polym 75:125-129. doi:10.1016/j.carbpol.2008.07.008

Billamboz N, Nedelec J-M, Grivet M, Baba M (2005) Crosslinking of polyolefins: a study by thermoporosimetry with benzene derivatives as swelling solvents. ChemPhysChem 6:1126-1132. doi:10.1002/cphc.200400472

Brun M, Lallemand A, Quinson J-F, Eyraud C (1977) A new method for the simultaneous determination of the size and shape of pores: the thermoporometry. Thermochim Acta 21:59-88. doi:10.1016/0040-6031(77)85122-8

Cai J, Kimura S, Wada M, Kuga S, Zhang L (2008) Cellulose aerogels from aqueous alkali hydroxide-urea solution. ChemSusChem 1:149-154. doi:10.1002/cssc.200700039

Dessources AH, Hartmann S, Baba M, Huesing N, Nedelec JM (2012) Multiscale characterization of hierarchically organized porous hybrid materials. J Mater Chem 22:27132720. doi:10.1039/C1JM14905A

Ebner G, Schiehser S, Potthast A, Rosenau T (2008) Side reaction of cellulose with common 1-alkyl-3-methylimidazolium-based ionic liquids. Tetrahedron Lett 49:7322-7324. doi:10.1016/j.tetlet.2008.10.052

Fagerlund G (1973) Determination of pore size distribution by suction prosimetry. Matér Constr 6:191-201. doi:10.1007/ BF02479033

Gavillon R, Budtova T (2008) Aerocellulose: new highly porous cellulose prepared from cellulose- $\mathrm{NaOH}$ aqueous solutions. Biomacromolecules 9:269-277. doi:10.1021/ bm700972k

Gibbs JW (1928) The collected works of J. Willard Gibbs. Longmans, Green and Co., New Haven

Gibson LJ, Ashby MF (1982) The mechanics of three-dimensional cellular materials. Proc R Soc Lond A Mater 382:43-59. doi:10.1098/rspa.1982.0088

Hoepfner S, Ratke L, Milow B (2008) Synthesis and characterisation of nanofibrillar cellulose aerogels. Cellulose 15:121-129. doi:10.1007/s10570-007-9146-8

Innerlohinger J, Weber HK, Kraft G (2006) Aerocellulose: aerogels and aerogel-like materials made from cellulose. Macromol Symp 244:126-135. doi:10.1002/masy.20 0651212

Jeong Y et al (2005) Small-angle X-ray scattering from a dualcomponent organogel to exhibit a charge transfer interaction. J Colloid Interface Sci 283:113-122. doi:10. 1016/j.jcis.2004.08.179

Jin H, Nishiyama Y, Wada M, Kuga S (2004) Nanofibrillar cellulose aerogels. Colloids Surf A 240:63-67. doi:10. 1016/j.colsurfa.2004.03.007

Kuga S (1980) The porous structure of cellulose gel regenerated from calcium thiocyanate solution. J Colloid Interface Sci 77:413-417. doi:10.1016/0021-9797(80)90311-2

Kuhn W, Peterli E, Majer H (1955) Freezing point depression of gels produced by high polymer network. J Polym Sci 16:539-548. doi:10.1002/pol.1955.120168238

Kumar V, de la Luz Reus-Medina M, Yang D (2002) Preparation, characterization, and tabletting properties of a new cellulose-based pharmaceutical aid. Int $\mathrm{J}$ Pharm 235:129-140. doi:10.1016/S0378-5173(01)00995-4

Liebner F et al (2009) Cellulosic aerogels as ultra-lightweight materials. Part 2: synthesis and properties. Holzforschung 63:3. doi:10.1515/hf.2009.002

Liebner F, Aigner N, Schimper C, Potthast A, Rosenau T (2012a) Bacterial cellulose aerogels: from lightweight dietary food to functional materials. In: Liebner F, Rosenau $\mathrm{T}$ (eds) Functional materials from renewable sources, vol 1107. ACS Symposium Series, vol 1107. American Chemical Society, pp 57-74. doi:10.1021/bk-2012-1107. ch004

Liebner F et al (2012b) Shaped hemocompatible aerogels from cellulose phosphates: preparation and properties. Holzforschung 66:317-321. doi:10.1515/hf.2011.163

Liebner F, Pircher N, Schimper C, Haimer E, Rosenau T (2015) Cellulose-based aerogels. CRC Press, Boca Raton. ISBN 9781439898796

Liu R-G, Shen Y-Y, Shao H-L, Wu C-X, Hu X-C (2001) An analysis of lyocell fiber formation as a melt-spinning process. Cellulose 8:13-21. doi:10.1023/a:1016785410218

Massiot D et al (2002) Modelling one- and two-dimensional solid-state NMR spectra. Magn Reson Chem 40:70-76. doi:10.1002/mrc.984

Nam S et al (2016) Segal crystallinity index revisited by the simulation of X-ray diffraction patterns of cotton cellulose Ib and cellulose II. Carbohydr Polym 135:1-9. doi:10. 1016/j.carbpol.2015.08.035

Östlund Å, Lundberg D, Nordstierna L, Holmberg K, Nydén M (2009) Dissolution and gelation of cellulose in TBAF/ DMSO solutions: the roles of fluoride ions and water. Biomacromolecules 10:2401-2407. doi:10.1021/ bm900667q

Pirard R, Rigacci A, Maréchal JC, Quenard D, Chevalier B, Achard P, Pirard JP (2003) Characterization of hyperporous polyurethane-based gels by non-intrusive mercury porosimetry. Polymer 44:4881-4887. doi:10.1016/S00323861(03)00481-6

Pircher N et al (2015) Preparation and reinforcement of dualporous biocompatible cellulose scaffolds for tissue engineering. Macromol Mater Eng 300:911-924. doi:10.1002/ mame. 201500048

Röhrling J, Potthast A, Rosenau T, Lange T, Borgards A, Sixta H, Kosma P (2002) A novel method for the determination of carbonyl groups in cellulosics by fluorescence labeling. 2. Validation and applications. Biomacromolecules 3:969975. doi:10.1021/bm020030p 
Rojas J, López A, Gamboa Y, Gonzáles C, Montoya F (2011) Assessment of processing and polymorphic form effect on the powder and tableting properties of microcrystalline celluloses I and II. Chem Pharm Bull 59:603-607. doi:10. 1248/cpb.59.603

Rosenau T, Potthast A, Adorjan I, Hofinger A, Sixta H, Firgo H, Kosma P (2002) Cellulose solutions in $N$-methylmorpholine- $N$-oxide (NMMO) — degradation processes and stabilizers. Cellulose 9:283-291. doi:10.1023/A:1021127 423041

Rosenau T, Schmid P, Kosma P (2005) On the non-classical course of Polonowski reactions of $N$-benzylmorpholine- $N$ oxide (NBnMO). Tetrahedron 61:3483-3487. doi:10.1016/ j.tet.2005.02.001

Rudaz C, Courson R, Bonnet L, Calas-Etienne S, Sallée H, Budtova T (2014) Aeropectin: fully biomass-based mechanically strong and thermal superinsulating aerogel. Biomacromolecules. doi: $10.1021 / \mathrm{bm} 500345 \mathrm{u}$

Ruland W (2001) Apparent fractal dimensions obtained from small-angle scattering of carbon materials. Carbon 39:323-324. doi:10.1016/S0008-6223(00)00256-6

Schelosky N, Roeder T, Baldinger T (1999) Molmassenverteilung cellulosischer Produkte mittels Groessenausschlusschromatographie in DMAc/LiCl (Molecular mass distribution of cellulosic products by size exclusion chromatography in DMAc/LiCl). Das Papier 53:728-738

Schimper C, Haimer E, Wendland M, Potthast A, Rosenau T, Liebner F (2011) The effects of different process parameters on the properties of cellulose aerogels obtained via the Lyocell route. Lenzing Ber 89:109-117

Sescousse R, Gavillon R, Budtova T (2011) Aerocellulose from cellulose-ionic liquid solutions: preparation, properties and comparison with cellulose- $\mathrm{NaOH}$ and celluloseNMMO routes. Carbohydr Polym 83:1766-1774. doi:10. 1016/j.carbpol.2010.10.043

Sugiyama J, Vuong R, Chanzy H (1991) Electron diffraction study on the two crystalline phases occurring in native cellulose from an algal cell wall. Macromolecules 24:4168-4175. doi:10.1021/ma00014a033

Thomson W (1872) 4. On the equilibrium of vapour at a curved surface of liquid. Proc R Soc Edinb 7:63-68. doi:10.1017/ S0370164600041729

Xu X, Liu F, Jiang L, Zhu JY, Haagenson D, Wiesenborn DP (2013) Cellulose nanocrystals vs. cellulose nanofibrils: a comparative study on their microstructures and effects as polymer reinforcing agents. ACS Appl Mater Interfaces 5:2999-3009. doi:10.1021/am302624t

Zhang L, Ruan D, Zhou J (2001) Structure and properties of regenerated cellulose films prepared from cotton linters in $\mathrm{NAOH} /$ urea aqueous solution. Ind Eng Chem Res 40:5923-5928. doi:10.1021/ie0010417

Zhang J, Cao Y, Feng J, Wu P (2012) Graphene-oxide-sheetinduced gelation of cellulose and promoted mechanical properties of composite aerogels. J Phys Chem C 116:8063-8068. doi:10.1021/jp2109237 